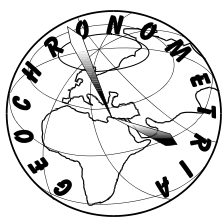

Conference Proceedings of the $4^{\text {th }}$ Asia Pacific Luminescence and Electron Spin Resonance Dating Conference Nov $23^{\text {rd }}-25^{\text {th }}$, 2015, Adelaide, Australia

Guest Editor: Mathieu Duval

\title{
ELECTRON SPIN RESONANCE SIGNALS OF QUARTZ IN PRESENT-DAY RIVER BED SEDIMENTS AND POSSIBLE SOURCE ROCKS IN THE KIZU RIVER BASIN, WESTERN JAPAN
}

\author{
AIKO SHIMADA ${ }^{\mathbf{1}}$, MASASHI TAKADA ${ }^{\mathbf{2}}$ and SHIN TOYODA ${ }^{\mathbf{3}}$ \\ ${ }^{I}$ JEOL RESONANCE Inc., 1-2 Musashino 3-Chome Akishima Tokyo, 196-8558, Japan \\ ${ }^{2}$ Faculty of Letters, Nara Women's University, Kitauoyanishimachi, Nara, 630-8506, Japan \\ ${ }^{3}$ Department of Applied Physics, Okayama University of Science, 1-1 Ridai, Okayama, 700-0005, Japan
}

Received 17 February 2016

Accepted 26 August 2016

\begin{abstract}
In this study, measurements of electron spin resonance (ESR) signals from quartz grains from present-day river bed sediments of the Kizu River basin (western Japan) were used to estimate the mixing ratios of the possible source materials of these fluvial deposits. The dose-saturated ESR signal intensities obtained from the $\mathrm{Al}$ and $\mathrm{Ti}-\mathrm{Li}$ centers in quartz grains were close to the range between the maximum and minimum intensities of their potential source rocks, meaning it was possible to estimate the mixing ratios of these sources. The results indicate that the dose-saturated $\mathrm{Al}$ and Ti-Li center ESR intensities can be used to quantitatively estimate the provenance of the sediments deposited by the Kizu River.
\end{abstract}

Keywords: ESR, quartz, sediment provenance, source rocks, river bed sediments.

\section{INTRODUCTION}

Electron spin resonance (ESR) signals, thermoluminescence (TL), and optically stimulated luminescence (OSL) have all been used to date material from the Quaternary (Ikeya et al., 1983; Aitken, 1985, 1998; Ikeya, 1993). Recently, a method has been developed that uses ESR and TL signals as indicators of sediment provenance (Ganzawa et al., 1997). Sediment provenance provides important information related to mountain uplift, environmental change in drainage basins, and crustal move-

Corresponding author: A. Shimada

e-mail: ashimada@jeol.co.jp ment.

The $\mathrm{E}_{1}$ ' center intensity of quartz can be used to investigate the provenance of aeolian dust (Naruse et al., 1997; Toyoda and Naruse, 2002; Nagashima et al., 2007). The heat-treated $\mathrm{E}_{1}{ }^{\prime}$ center signal intensity, which corresponds to the number of oxygen vacancies in natural volcanic and granitic quartz, is correlated with age, with higher values found in the quartz of older source rocks (Toyoda and Hattori, 2000; Toyoda and Naruse, 2002). The Al, Ti$\mathrm{Li}$, and $\mathrm{E}_{1}{ }^{\prime}$ center signal intensities of quartz are useful in determining sediment provenance (Duttine et al., 2002; Shimada and Takada, 2008; Shimada et al., 2013). The $\mathrm{Al}$ center is an electron hole trapped at the bond between oxygen atoms and $\mathrm{Al}$ impurity atoms (the latter having replaced Si in the quartz crystal; O'Brien, 1955). The TiLi center is an electron trapped at $\mathrm{Ti}$, which can also 
replace $\mathrm{Si}$ in the quartz crystal, together with an accompanying Li ion (Wright et al., 1963). As Usami (2010) showed that the ESR signal intensity of the Al center positively correlates with the concentration of $\mathrm{Al}$ in quartz (on the order of ppm), the ESR signal intensity of the impurity centers is related to the amount of impurities in the quartz crystals, and so indicates the geochemical and geophysical conditions of quartz crystallization.

As no $E_{1}^{\prime}$ center is observed in quartz crystals from young bedrock, the amount of the various impurities in quartz is a useful index for estimating the provenance of sediments of Quaternary volcanic origin (Shimada and Takada, 2008; Shimada et al., 2013). Shimada et al. (2013) showed that the diagram of Al versus Ti-Li centers signal intensities from the same grain size can be used to roughly distinguish Quaternary volcanic sediments from granitic rocks. Tissoux et al. (2015) showed that the method using ESR signals makes it possible to discriminate quartz grains of different geological sources from one another.

In this study, we investigate the relationships among ESR signals of quartz in modern river bed sediments and bedrocks of the Kizu River basin using the dose-saturated signal intensities of the $\mathrm{Al}$ and Ti-Li centers. In addition, we use these ESR signal intensities to estimate the mixing ratios of the source materials that make up the river bed sediments.

\section{REGIONAL GEOLOGY AND SAMPLING}

Bedrock is broken down by weathering into unconsolidated materials, which are then carried downstream by rivers. In this study, modern river bed sediments and bedrock samples were collected at sites S1-S7and R1R5, respectively, from the Kizu River basin, western Japan (Fig. 1). The total length of the Kizu River is $89 \mathrm{~km}$, and the basin covers an area of $1663 \mathrm{~km}^{2}$.

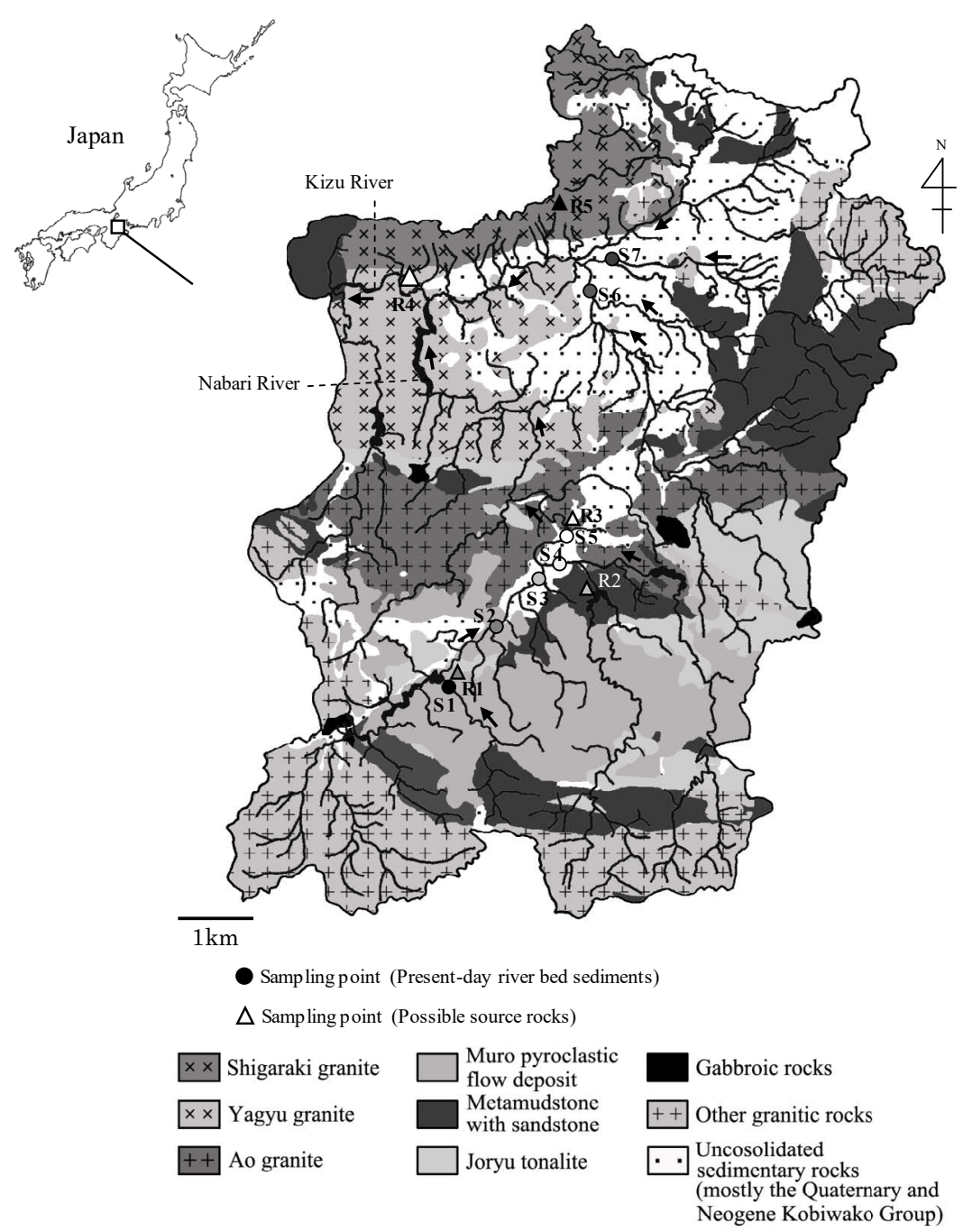

Fig. 1. Location map showing sample sites for the present-day river bed sediments and the possible source rocks around the Kizu River, Japan.

R1 - Muro pyroclastic flow deposits;

R2 - Metamudstone with sandstone;

R3 - Ao granite;

R4 - Yagyu granite;

R5 - Shigaraki granite;

S1-S7 - Present-day river bed sediments. 
Samples S1-S5 and R1-R3 were collected along the Nabari River, one of the large tributaries of the Kizu River in the southern part of the basin. Samples S6-S7 and R4-R5 were collected along the main course of the Kizu River. Muro pyroclastic flow deposits (sample R1) are widely distributed in the upper (southern) section of the Nabari River and along the main course of the Kizu River. Metamudstone with sandstone (sample R2) from the mid-Paleozoic Tamba Belt is distributed in the upper (southern) and middle reaches of the Nabari River, and along the main course of the Kizu River. Ao granite (sample R3) and Yagyu granite (sample R4) are widely distributed along the middle reaches of the Nabari River and along the main course of the Kizu River, and Shigaraki granite (sample R5) is found in the lower (northern) basin of the Kizu River (Fig. 1). The bedrock in the northern part of the drainage basin includes the Quaternary and Neogene Kobiwako Group, whereas the southern part of the basin comprises the Joryu tonalite and other granitic rocks. Although other rock types are present in the study area, the rock types defined as R1 to R5 are dominant, which suggests that the modern river bed sediments are derived mostly from these basement rocks.

\section{SAMPLES AND EXPERIMENTS}

\section{Sample preparation}

Quartz particles in fluvial sediments are moved downstream by the tractive force of the river. Therefore, in this study we used sand-sized quartz grains from river bed sediments of the Kizu River to estimate the composition and sources of these deposits. The samples of crushed rocks and river sediments were sieved to separate out the $500 \mu \mathrm{m}$ and $1 \mathrm{~mm}$ fractions. Magnetic minerals were removed using a magnetic separator. The sieved samples were treated with $6 \mathrm{M}$ hydrochloric acid $(\mathrm{HCl})$ overnight, and then with a $1 \% \mathrm{HF}$ and $1 \% \mathrm{HNO}_{3}$ mixture for $12 \mathrm{~h}$, prior to heavy liquid (sodium polytungstate solution) separation. The quartz grains were etched with $46 \% \mathrm{HF}$ for $1 \mathrm{~h}$ to dissolve any contaminating feldspar and then treated with $6 \mathrm{M} \mathrm{HCl}$ overnight. Finally, the samples were crushed and re-sieved into fractions containing 120 and $250 \mu \mathrm{m}$ quartz grains.

\section{Gamma ray irradiation}

The ESR dose response curves of quartz grains from impurity centers are known to grow with high radiation doses (Yokoyama et al., 1985). Therefore, we used the dose-saturated ESR signal intensities. To obtain the additive dose responses of the signals, subsamples of quartz samples R2, R3, and S4 were divided into 6-9 aliquots. They were then irradiated using a ${ }^{60} \mathrm{Co}$ gamma ray source with doses ranging from 0.2 to $3 \mathrm{kGy}$ and a dose rate of $100 \mathrm{~Gy} / \mathrm{h}$ at the Takasaki Research Institute of the Japan Atomic Energy Agency. Based on the results from these irradiated samples, all samples were irradiated to a dose of $2.5 \mathrm{kGy}$ at a dose rate of $100 \mathrm{~Gy} / \mathrm{h}$ to obtain the dosesaturated signal intensities.

\section{ESR measurement}

ESR measurements were conducted using a JESX320 X-band spectrometer (JEOL RESONANCE Inc.) with the Liquid Helium Variable Temperature System (ES-CT470). The $\mathrm{Al}$ and Ti-Li center signals from the quartz samples were measured at $77 \mathrm{~K}\left(-196^{\circ} \mathrm{C}\right)$ using a microwave power of $5 \mathrm{~mW}$, a sweep time of $2 \mathrm{~min}$, a time constant of $0.03 \mathrm{~s}$, an amplitude of field modulation of $0.1 \mathrm{mT}$, and a modulation frequency of $100 \mathrm{kHz}$. Fig. 2 shows the ESR spectrum of sample R1 at $77 \mathrm{~K}$. We took the relative height from the top of the first peak to the bottom of the $16^{\text {th }}$ peak of the main hyperfine structures as the $\mathrm{Al}$ center intensity (Yokoyama et al., 1985; Toyoda and Falguères, 2003; Shimada and Toyoda, 2004), and the relative height from the baseline to the peak at the bottom of the $\mathrm{g}=1.913$ point as the Ti-Li center intensity (Toyoda et al., 2000). Given that the peroxy center signal at $\mathrm{g}=2.067$ overlaps the $\mathrm{Al}$ center signal, Toyoda and Falguères (2003) suggested taking the peak height between $g=2.018$ and 1.993 as the $\mathrm{Al}$ center signal intensity to avoid the contribution from the peroxy center signal. To calculate the g values of the ESR signals, and to further check the sensitivity of the ESR spectrometer, we used the intensity of a standard $\mathrm{MnO}$ marker inside the cavity. Each sample was measured five times, and the sample tube was rotated in the cavity to average the angular dependence of the ESR signals. For normalization and sensitivity correction, the average peak intensities were divided by the weight of the sample and by the standard $\mathrm{MnO}$ marker signal intensity, which was measured together with the sample.

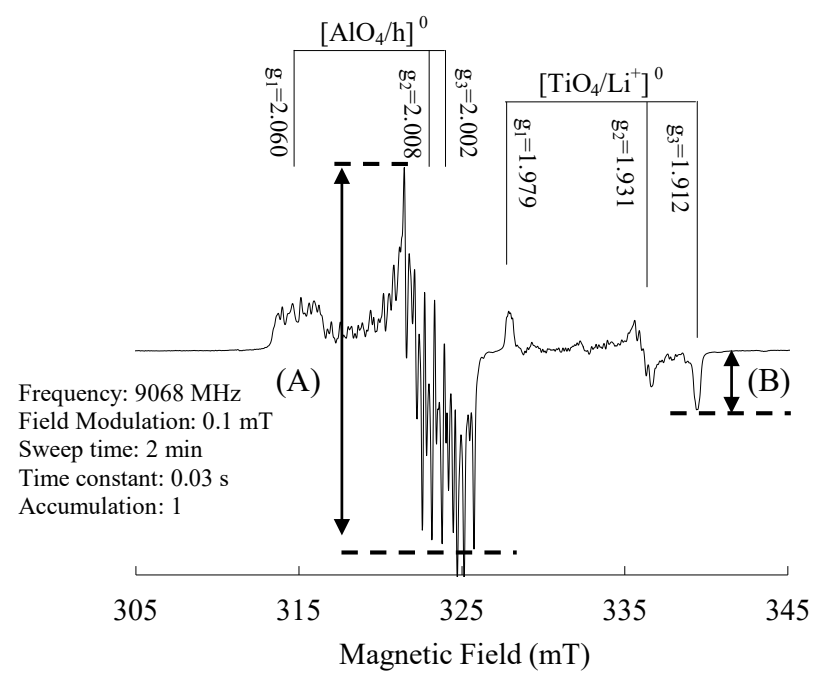

Fig. 2. Al and Ti-Li center signals observed at $77 \mathrm{~K}$ for quartz in the Muro pyroclastic flow deposits. (A) Al center signal intensity. (B) Ti-Li center signal intensity. 


\section{RESULTS AND DISCUSSION}

\section{Gamma ray dose response of ESR signal intensity}

The Al and Ti-Li center signal intensities obtained from the quartz of the metamudstone with sandstone sample R2 and the river sediment sample S4 increased with the gamma ray dose, becoming almost saturated above $2.5 \mathrm{kGy}$ (Fig. 3A, 3B). The intensities obtained from the quartz in the granitic samples (R3) were almost saturated with gamma ray doses above 2 kGy (Fig. 3A, 3B). Different samples may have received different accumulated natural doses that cause the signal intensities to differ; therefore, to erase the effect of different natural radiation doses, we used a dose of $2.5 \mathrm{kGy}$ in order to reach the saturation for all samples.
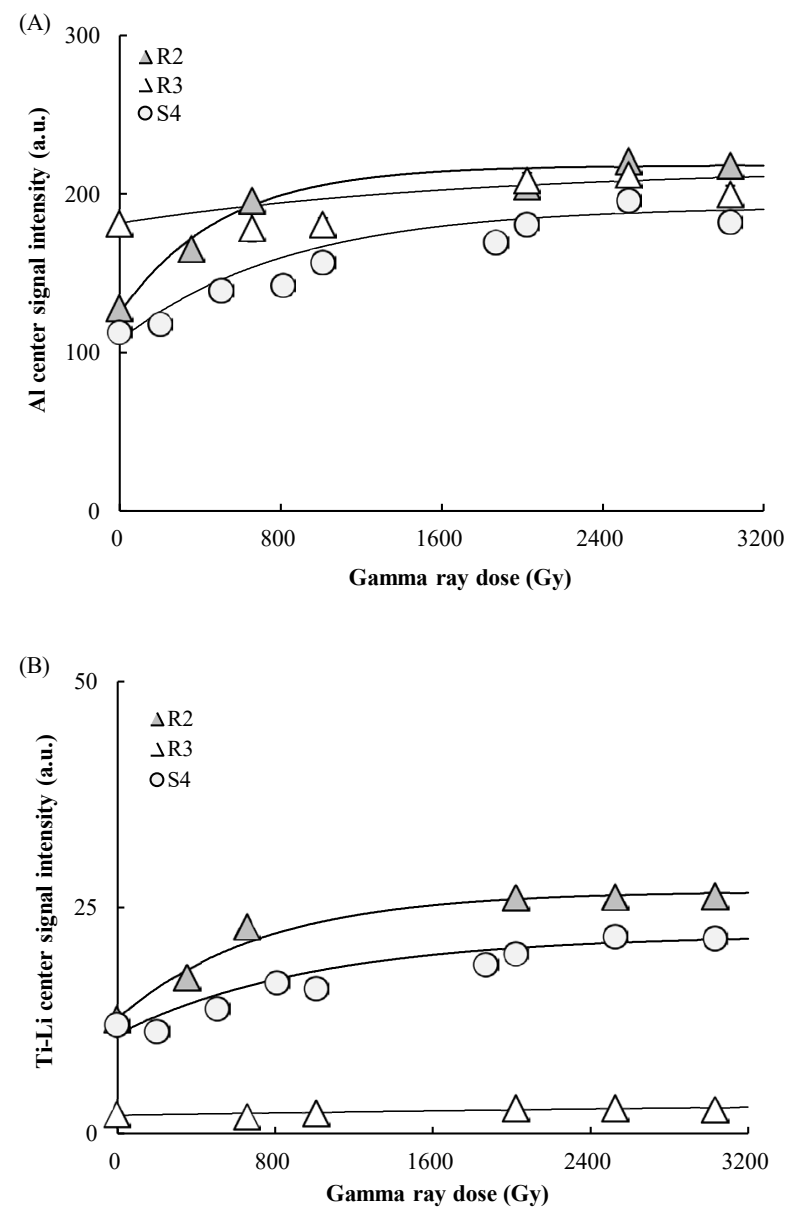

Fig. 3. Comparison of additive dose curves of $\mathrm{Al}$ and Ti-Li centers. (A) Al center signal intensity. (B) Ti-Li center signal intensity.

\section{Variations in ESR signal intensities within the same sample}

Each sample was divided into five aliquots and then each aliquot was measured five times to investigate variations in the $\mathrm{Al}$ and Ti-Li center signal intensity of the quartz in the same sample. Deviations of the $\mathrm{Al}$ and $\mathrm{Ti}-\mathrm{Li}$ center signal intensity from the quartz from the presentday river bed sediments (S1-S7) and bedrock (R1-R5) samples were between $1 \%$ and $6 \%$ in a given sample (Table 1). The repeated measurement error for each sample was within $\pm 11 \%$. Therefore, when the difference in the signal intensities between the different samples was larger than this measurement error, we assumed that the samples were indeed different.

Table 1. Sample numbers and names, and ESR signal intensities.

\begin{tabular}{lccc}
\hline Sample & Name & $\begin{array}{c}\text { Al center signal } \\
\text { intensity } \\
\text { (a.u.) }\end{array}$ & $\begin{array}{c}\text { Ti-Li center } \\
\text { signal intensity } \\
\text { (a.u.) }\end{array}$ \\
\hline R1 & $\begin{array}{c}\text { Muro pyroclastic flow } \\
\text { deposits }\end{array}$ & $384 \pm 11.8$ & $72 \pm 0.3$ \\
\hline R2 & $\begin{array}{c}\text { Metamudstone } \\
\text { with sandstone }\end{array}$ & $217 \pm 3.2$ & $24 \pm 0.6$ \\
\hline R3 & Ao granite & $210 \pm 6.1$ & $2 \pm 0.1$ \\
\hline R4 & Yagyu granite & $89 \pm 1.3$ & $17 \pm 0.5$ \\
\hline R5 & Shigaraki granite & $82 \pm 2.1$ & $6 \pm 0.1$ \\
\hline S1 & Present river sediment-1 & $225 \pm 10.1$ & $36 \pm 1.0$ \\
\hline S2 & Present river sediment-2 & $219 \pm 7.5$ & $28 \pm 1.1$ \\
\hline S3 & Present river sediment-3 & $286 \pm 3.9$ & $42 \pm 0.9$ \\
\hline S4 & Present river sediment-4 & $192 \pm 6.1$ & $21 \pm 1.0$ \\
\hline S5 & Present river sediment-5 & $226 \pm 5.3$ & $28 \pm 2.0$ \\
\hline S6 & Present river sediment-6 & $206 \pm 5.8$ & $22 \pm 0.9$ \\
\hline S7 & Present river sediment-7 & $177 \pm 7.5$ & $24 \pm 1.7$ \\
\hline & & &
\end{tabular}

\section{ESR signal intensities in artificially mixed quartz samples}

When two sources of quartz with ESR signal intensities $\mathrm{a}$ and $\mathrm{b}$ are combined with a mixing ratio of $\mathrm{x}$ : $(1-$ $\mathrm{x}$ ), the ESR signal intensity, $c$, of the mixed sample can be expressed as follows:

$c=a x+b(1-x)$

To investigate variations in the $\mathrm{Al}$ and $\mathrm{Ti}-\mathrm{Li}$ center signal intensity of the quartz in the volcanic (R1) and granitic (R5) samples, we tested five mixed samples based on the following $\mathrm{x}$ values (i.e., \% R1): 100, 75, 50, 25 , and 0 . The ESR signal intensities varied with the mixing ratios (Fig. 4; Table 2). The ESR signal intensity of a sample consisting of material of two different origins is affected by the signal from both sources. The ESR signal intensities linearly increased or decreased with the mixing ratios of the samples (Fig. 5A, 5B). Therefore, it is possible to estimate the provenance of these sediments 


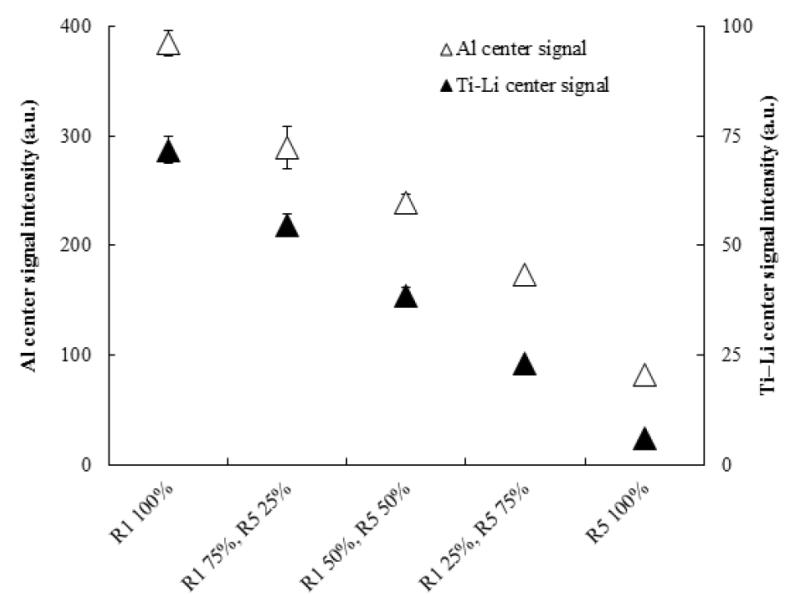

Fig. 4. Change in the Al versus Ti-Li center signal intensities for quartz caused by changing the mixing ratio of the samples (samples $R 1$ and $R 5 ; n=5)$.

by measuring the ESR signal intensities of quartz crystals found in the river sediments and related bedrock.

\section{ESR signal intensities of quartz in the river bed sedi- ments and possible source rocks}

The dose-saturated ESR intensities of samples S1-S7 and R1-R5 are shown in Fig. 5 and Table 1. The Al and Ti-Li center signal intensities of sample R1 (Muro pyroclastic flow deposits) are the highest among all the samples. The $\mathrm{Al}$ and Ti-Li center signal intensities of sample R2 (metamudstone with sandstone) plot between those for R1 (Muro pyroclastic flow deposits) and R3 (Ao granite) or R5 (Shigaraki granite) on the $\mathrm{Al}$ versus $\mathrm{Ti}-\mathrm{Li}$ signal diagram. The Ti-Li center signal intensity of sample R3 (Ao granite) is the lowest among these samples, whereas the Al center signal intensity of sample R5 (Shigaraki granite) is the lowest of all the samples. The $\mathrm{Al}$ and $\mathrm{Ti}-\mathrm{Li}$ center signal intensities of quartz in the modern river bed sediments plot within the quadrilateral area bounded by R1, R3, R4, and R5 on the Al versus Ti-Li signal diagram (Fig. 5), indicating that the present-day river bed sediments are a mixture of the source rocks within the drainage basin.

\section{Mixing ratios of the present-day river bed sediments}

As shown in Fig. 1, the Muro pyroclastic flow deposits (R1) and metamudstone with sandstone (R2) are widely distributed around sampling sites S1 and S2, and in the upstream basin, suggesting that R1 and R2 are the main sources of the quartz deposited at sites S1 and S2. Using Eq. 4.1 and the $\mathrm{Al}$ center signal intensities, the mixing ratios are 0.05:0.95 for $\mathrm{R} 1: \mathrm{R} 2$ in sample $\mathrm{S} 1$, and 0.01:0.99 for R1:R2 in sample S2 (Table 3). However, using Eq. 4.1 and the Ti-Li center signal intensities, these ratios are $0.23: 0.77$ for $\mathrm{R} 1: \mathrm{R} 2$ in sample $\mathrm{S} 1$, and
Table 2. ESR signal intensities of artificially mixed samples created by mixing samples $R 1$ and $R 5(n=5)$.

\begin{tabular}{lcccc}
\hline & $\begin{array}{c}\text { R1 mixting } \\
\text { ratio }\end{array}$ & $\begin{array}{c}\text { R5 mixting } \\
\text { ratio }\end{array}$ & $\begin{array}{c}\text { Al center } \\
\text { signal } \\
\text { intensity } \\
\text { (a.u.) }\end{array}$ & $\begin{array}{c}\text { Ti-Li center } \\
\text { signal } \\
\text { intensity } \\
\text { (a.u.) }\end{array}$ \\
\hline \multirow{3}{*}{ Estimated data } & $\mathbf{( \% )}$ & $(\%)$ & 158 & 22 \\
& 25 & 75 & 233 & 39 \\
& 50 & 50 & 309 & 55 \\
\hline \multirow{5}{*}{ Experimental } & 25 & 100 & 82 & 6 \\
data & 0 & 75 & 174 & 23 \\
& 50 & 50 & 239 & 38 \\
& 75 & 25 & 290 & 55 \\
& 100 & 0 & 384 & 72 \\
\hline
\end{tabular}

0.08:0.92 for R1:R2 in sample S2 (Table 3). The mixing ratios calculated using the $\mathrm{Al}$ center signal should be the same as those calculated using the Ti-Li center signal; therefore, the discrepancy between them suggests that the contribution from other source materials is not negligible.

As for samples S3, S4, and S5, there would be additional large contributions from the Ao granite (R3) that crops out in the upstream section of the river above these three sampling sites. When three sources with $\mathrm{Al}$ and $\mathrm{Ti}-$ Li center signal intensities a and a', b and b', and c and c' mix in the ratio x:y:z, the resultant signal intensity of the $\mathrm{Al}$ (d) and $\mathrm{Ti}-\mathrm{Li}$ (d') center can be expressed as follows:

$\mathrm{d}=\mathrm{ax}+\mathrm{by}+\mathrm{cz}$

$\mathrm{d}^{\prime}=\mathrm{a}^{\prime} \mathrm{x}+\mathrm{b}^{\prime} \mathrm{y}+\mathrm{c}^{\prime} \mathrm{z}$

where

$\mathrm{x}+\mathrm{y}+\mathrm{z}=1$

In Table 3, we show the results of these calculations for samples S3-S7.

The mixing ratio R1:R2:R3 for $\mathrm{S} 3$ was calculated using Eqs. 2-4 from the ESR signal intensities of samples R1 (Muro pyroclastic flow deposits), R2 (the

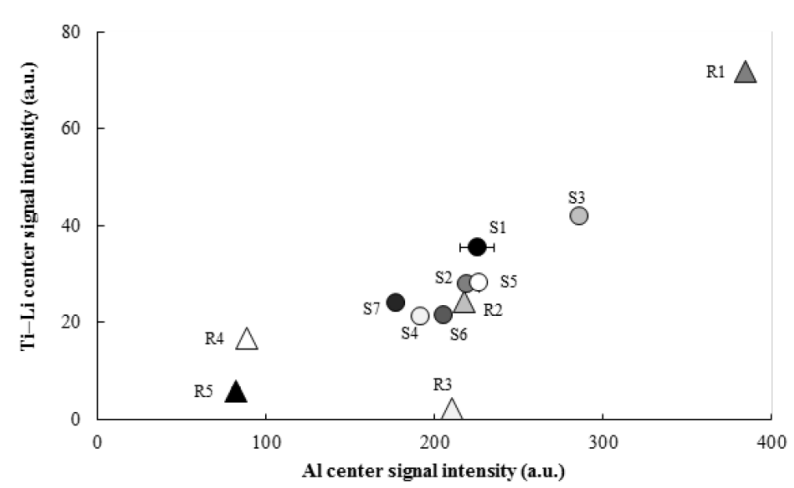

Fig. 5. Al versus Ti-Li center signal intensities for quartz from the present-day river bed sediments and possible source rocks. 
Table 3. Mixing ratios of the present-day river bed sediments and ESR signal intensities of the samples.

\begin{tabular}{|c|c|c|c|}
\hline Sample & $\begin{array}{l}\text { Major possible } \\
\text { source rocks } \\
\text { and sediments }\end{array}$ & $\begin{array}{l}\text { Mixting ratio (\%) } \\
\text { estimated from Al } \\
\text { center signal inten- } \\
\text { sities }\end{array}$ & $\begin{array}{l}\text { Mixting ratio (\%) } \\
\text { estimated from Ti-Li } \\
\text { center signal intensi- } \\
\text { ties }\end{array}$ \\
\hline \multirow{2}{*}{ S1 } & R1 & 5 & 23 \\
\hline & R2 & 95 & 77 \\
\hline \multirow{2}{*}{ S2 } & R1 & 1 & 8 \\
\hline & R2 & 99 & 92 \\
\hline \multirow{3}{*}{ S3 } & R1 & \multicolumn{2}{|c|}{42} \\
\hline & R2 & \multicolumn{2}{|c|}{49} \\
\hline & R3 & \multicolumn{2}{|c|}{9} \\
\hline \multirow{3}{*}{ S4 } & R1 & \multicolumn{2}{|c|}{-16} \\
\hline & R2 & \multicolumn{2}{|c|}{137} \\
\hline & R3 & \multicolumn{2}{|c|}{-21} \\
\hline \multirow{3}{*}{ S5 } & R1 & \multicolumn{2}{|c|}{5} \\
\hline & R2 & \multirow{2}{*}{\multicolumn{2}{|c|}{102}} \\
\hline & R3 & & -7 \\
\hline \multirow{3}{*}{ S5 } & S3 & 36 & 33 \\
\hline & S4 & 64 & 67 \\
\hline & R2 & \multicolumn{2}{|c|}{86} \\
\hline \multirow[t]{2}{*}{ S6 } & R3 & \multicolumn{2}{|c|}{6} \\
\hline & R4 & \multicolumn{2}{|r|}{8} \\
\hline \multirow{3}{*}{ S7 } & R2 & \multicolumn{2}{|c|}{68} \\
\hline & R4 & \multirow{2}{*}{\multicolumn{2}{|c|}{53}} \\
\hline & R5 & & \\
\hline
\end{tabular}

metamudstone with sandstone), and R3 (Ao granite) as 0.42:0.49:0.09; however, the mixing ratios for S4 and S5 include unrealistic negative values, suggesting a significant contribution from other source materials.

Sample site S5 is located downstream from the junction of two rivers, one of which flows through site $\mathrm{S} 3$ and the other through S4 (Fig. 1). The locations of S3, S4, and S5 are almost collinear (see Fig. 5). Therefore, the location of site S5 suggests that the present-day river bed sediments from sites S3 and S4 have mixed to form the deposits sampled at $\mathrm{S} 5$. If we use the $\mathrm{Al}$ center signal intensities, the estimated mixing ratio of $\mathrm{S} 3: \mathrm{S} 4$ in sample S5 is $0.36: 0.64$, and using the Ti-Li center signal intensities the mixing ratio is $0.33: 0.67$. As the two mixing ratios are almost the same, we suggest that the source materials and their mixing ratio are predominant. Thus, it is possible to estimate the mixing ratios of the source rocks and of the present-day river bed sediments by using the ESR signal intensities. The results of present analysis (Fig. 5) would indicate that the ESR signal intensities of river sediments are strongly affected by the nearby rocks (such as S2). However, the locations of S1 to 5 in Fig. 5 are not exactly within the range of the locations of R1 to 3 which are the possible original rock sources analyzed in the present study, but might indicate that there is still another source with higher $\mathrm{Ti}-\mathrm{Li}$ and lower $\mathrm{Al}$ center signal intensities. A possible major rock source would be Joryu tonalite (Fig. 1), which has not yet been analyzed.
As shown in Fig. 1, the metamudstone with sandstone (R2), Ao granite (R3), and Yagyu granite (R4) are distributed around, and upstream from, site S6 suggesting that the quartz deposited at S6 is derived from these source rocks. If we use the $\mathrm{Al}$ and $\mathrm{Ti}-\mathrm{Li}$ center signal intensities, the mixing ratio of $\mathrm{R} 2: \mathrm{R} 3: \mathrm{R} 4$ for sample $\mathrm{S} 6$ is 0.86:0.06:0.08 (Table 3). In a similar way, the metamudstone with sandstone (R2), Yagyu granite (R4), and Shigaraki granite (R5) are distributed around, and upstream from, site S7, suggesting that the quartz deposited at $\mathrm{S} 7$ is derived from these source rocks. If we use the ESR signal intensities, the mixing ratio of $\mathrm{R} 2: \mathrm{R} 4: \mathrm{R} 5$ for sample S7 is 0.68:0.53:-0.21 (Table 3). As the mixing ratio for sample $\mathrm{S} 7$ includes an unrealistic negative value, we suggest that the contribution from other source materials is significant.

We made a tentative estimate of the mixing ratios using the ESR $\mathrm{Al}$ and $\mathrm{Ti}-\mathrm{Li}$ center signal intensities from only the $0.5-1.0 \mathrm{~mm}$ fraction of the quartz grains in the present-day river sediments; however, to quantitatively estimate the precise provenance of sediments we should consider the composition, grain size distributions, and sorting during transportation of the minerals in the sediments. These tasks will be the subject of a future investigation.

\section{CONCLUSIONS}

The dose-saturated ESR signal intensities of quartz grains from samples of present-day river bed sediments in the Kizu River plot overlap with those of possible source bedrocks in a $\mathrm{Al}$ versus Ti-Li signal diagram (Fig. 5), indicating that the modern river bed sediments are a mixture of the source materials distributed across the drainage basin. We estimated the mixing ratios of the possible bedrock sources from the ESR signal intensities (Table 3). Consequently, we were able to quantitatively estimate the provenance of the present-day river bed sediments using the dose-saturated $\mathrm{Al}$ and Ti-Li center signal intensities of quartz grains recovered from the sediments.

\section{ACKNOWLEDGEMENTS}

We thank anonymous reviewers for their valuable comments. This work was supported by JSPS KAKENHI (grant number 23300338 and 15H02960) and by the Inter-University Program for the Joint Use of JAEA Facilities, and also partly by the MEXT-Supported Program for the Strategic Research Foundation at Private Universities (2011-2015).

\section{REFERENCES}

Aitken MJ, 1985. Thermoluminescence dating. Academic Press, London, $359 \mathrm{pp}$.

Aitken MJ, 1998. An introduction to optical dating. Oxford Science Publications, Oxford, 267pp. 
Duttine M, Villeneuvea G, Bechtela F and Demazeaub, G, 2002. Caractérisation par resonance paramagnétique électronique (RPE) de quartz naturels issus de différentes sources. C. R. Geoscience 334: 949-955 (in French).

Ganzawa Y, Watanabe Y, Osanai F and Hashimoto T, 1997. TL color images from quartzes of loess and tephra in China and Japan. $R a-$ diation Measurements 27: 383-388, DOI 10.1016/S13504487(96)00129-1.

Ikeya M, Miki T and Tanaka K, 1983. Dating of a fault by electron spin resonance on intra-fault materials. Science 215: 1392-1293, DOI 10.1126/science.215.4538.1392.

Ikeya M, 1993. New Applications of Electron Spin Resonance, Dating, Dosimetry, and Microscopy. World Scientific, Singapore, 500pp.

Nagashima K, Tada R, Tani A, Toyoda S, Sun Y and Isozaki Y, 2007. Contribution of aeolian dust in Japan Sea sediments estimated from ESR signal intensity and crystallinity of quartz. Geochemistry, Geophysics, Geosystems 8: Q02Q04, DOI 10.1029/2006GC001364.

Naruse T, Ono Y, Hirakawa K, Okashita M and Ikeya M, 1997. Source areas of eolian dust quartz in East Asia: a tentative reconstruction of prevailing winds in isotope stage 2 using electron spin resonance. Geographical Review of Japan 70(A1): 15-27.

O'Brien MCM, 1955. The structure of the color centers in smoky quartz. Proceedings of the Royal Society of London A 231: 404414, DOI 10.1098/rspa.1955.0183.

Shimada A and Toyoda S, 2004. The optimal conditions of microwave and temperature of ESR measurement suitable for impurities centers in quartz. Advances in ESR Applications 21: 13-16.

Shimada A and Takada M, 2008. Characteristics of Electron Spin Resonance (ESR) signals in quartz from igneous rock samples: a clue to sediment provenance. Annual Reports of the Graduate
School of Humanities and Sciences 23: 187-195.

Shimada A, Takada M and Toyoda S, 2013. Characteristics of ESR signals and TLCLs of quartz included in various source rocks and sediments in Japan: a clue to sediment provenance. Geochronometria 40(4): 334-340, DOI 10.2478/s13386-013-0111-z.

Tissoux H, Voinchet P, Lacquement F and Despriée J, 2015. ESR as a method for the characterization of alluvial sediments. Radiation Measurements 81: 2-8, DOI 10.1016/j.radmeas.2015.05.010.

Toyoda S and Hattori M, 2000. Formation and decay of the $\mathrm{E}_{1}$ ' center and of its precursor. Applied Radiation Isotopes 52: 1351-1356, DOI 10.1016/S0969-8043(00)00094-4.

Toyoda S and Naruse T, 2002. Eolian Dust from Asia deserts to Japanese Islands since the last Glacial Maximum: the Basis for the ESR Method. Japan Geomorphological Union 23-5: 811-820.

Toyoda $\mathrm{S}$ and Falguères $\mathrm{C}, 2003$. The method to represent the ESR intensity of the aluminium hole center in quartz for the purpose of dating. Advances in ESR Applications 20: 7-10.

Toyoda S, Voinchet P, Falguères C, Dolo JM and Laurent M, 2000. Bleaching of ESR signals by sunlight: a laboratory experiment for establishing the ESR dating of sediments. Applied Radiation and Isotopes 52(5): 1357-1362, DOI 10.1016/S0969-8043(00)00095-6.

Usami T, 2010. Interaction Between Paramagnetic Diffusion Quartz and Effects by Pressure (in Japanese, Japanese title translated). $\mathrm{PhD}$ Thesis, Okayama University of Science. Okayama, JPN.

Yokoyama Y, Falguères C and Quaegebeur JP, 1985. ESR dating of quartz from quaternary sediments: first attempt. Nuclear Tracks and Radiation Measurements 10(4-6): 921-928, DOI 10.1016/0735-245X (85)90109-7.

Wright PM, Weil JA, Buch T and Anderson JH, 1963. Titanium color centers in rose quartz. Nature 197: 246-248, DOI $10.1038 / 197246 \mathrm{a} 0$. 